\title{
Maternal and Child Health Situation in South East Asia
}

\author{
Bhandari TR \\ Achutha Menon Centre for Health Science Studies, Sree Chitra Tirunal Institute for Medical Sciences and Technology, Trivandrum, \\ Kerala, India
}

\begin{abstract}
Attaining maternal and child health goals remains a challenge to the world. There is need to collect and manage reliable information on maternal and child health for resource generation and proper allocation. This is useful for assessing progress towards the Millennium Development Goals 4 and 5. This paper aims to assess the maternal and child health status in South East Asia Region.

Literature search from PubMed, Medline, Lancet, WHO and Google web pages published from 2000 to 2012 was the method adopted for review. All the related references were cited and organized by using referencing software Endnote.

Out of the South East Asian countries Thailand, South Korea, Sri-Lanka and Maldives have better maternal child health indicators. South Korea, Sri-Lanka and Maldives follow Thailand in almost indicators. Bangladesh, Bhutan, India, Indonesia, Myanmar, Nepal, and East Timor have poor indicators and are at the bottom of the group.

In the South East Asia, there is wide divergence in socio-economic and health status among the countries. More than one-third of maternal and child deaths of global mortality occurs in this region. Many countries in this region are unlikely to achieve the Millennium Development Goals 4 and 5 even if maternal child health is made the priority agenda of all the countries.
\end{abstract}

Keywords: Child Health, maternal health, millennium development goals, south east asia region.

\section{INTRODUCTION}

The South East Asia Region of the World Health Organization (WHO) comprises eleven countries: Bangladesh, Bhutan, Democratic People's Republic of Korea, India, Indonesia, Maldives, Myanmar, Nepal, SriLanka, Thailand and Timor-Leste with wide discrepancy in socio-economic characteristics. Over the last decade, the region as a whole and India in particular, has seen rapid changes in economic development. In spite of this, there is enormous inconsistency in public health expenditure across South East Asia Region member states. It reflects the priority given to health at a policy and planning level. ${ }^{1}$

\section{CORRESPONDENCE}

Tulsi Ram Bhandari, Ph D Scholar Achutha Menon Centre for Health Science Studies Sree Chitra Tirunal Institute for Medical Sciences and Technology Trivandrum, Kerala, India

Phone: 0091-9605657941

Email: tulsib2004@gmail.com
Reproductive health concerns lives from conception to birth, through adolescence to old age, and includes the achievement and continuation of good health as well as the prevention and treatment of illnesses. Its services cover a wide range of maternal and child health programs. Woman of reproductive age refers to all women aged 15-49 years. ${ }^{2}$ Reproductive health is defined as a state of complete physical, mental and social well-being and not merely the absence of disease or infirmity, in all matters relating to the reproductive system and to its functions and processes. ${ }^{3}$ Therefore, it entails the ability of the people to have a satisfying, safe sex, capability to reproduce and the freedom to decide in life. It is also concerned with sexual health for the enrichment of life and rapport with sexual partner. 
Maternal health care embraces antenatal, intranatal and postnatal care; quality intranatal care and is crucial to achieve the aim of a healthy mother and a healthy baby at the end of a pregnancy. ${ }^{4}$ Mostly, maternal mortality is measured by maternal mortality ratio, maternal mortality rate and lifetime risk of maternal death. Maternal mortality ratio and rate represent the risk associated with each pregnancy and its causes. Similarly, the lifetime risk of maternal death accounts probability of becoming pregnant and the risk of death due to pregnancy-related cumulated causes in a woman's reproductive age.

Millennium Development Goal- 5 concerns maternal health and aims to reduce by three quarters the maternal mortality ratio between the years 1990 and 2015. Estimate of WHO, UNICEF and UNFPA for the years 1990, 1995 and 2000 points out that more than half a million women die every year from complications of pregnancy and childbirth, of which more than $50 \%$ take place in Africa and $40 \%$ in Asia. $^{2}$

Anomalies and complications during pregnancy, childbirth and postnatal period are leading causes of death and disability among women of reproductive age in developing countries. Every day in the world, approximately one thousand women die from preventable causes related to pregnancy and childbirth, out of them $99 \%$ of all maternal deaths occur in developing countries. Maternal mortality is higher in rural areas and among poorer and less educated communities. Adolescents face a higher risk of complications and death as a result of pregnancy than older women. Skilled care during antenatal, intranatal and postnatal period can save the lives of mother and child. Between the years 1990 and 2008, maternal mortality worldwide dropped by one third. ${ }^{5}$ The common causes of maternal death are haemorrhages, infections, hypertensive disorders, obstructed labour and complications of unsafe abortion. In addition, three million neonatal deaths, representing about $40 \%$ of all under-five infant mortality occur every year. Three quarters of these neonatal deaths occur in the first week of life. Preterm birth, infections, and asphyxia were the major direct causes of neonatal deaths. ${ }^{6}$

The conceptualization and measurement of socioeconomic status is difficult in developing countries as lack of well managed data. ${ }^{7}$ Maternal, newborn and child health outcomes are the results of a number of social, cultural, economic, environmental determinants and other factors. Combining different components such as training, education, provision of supplies and upgrading of equipment, transport infrastructure may help to reduce maternal and child mortality. ${ }^{8}$ The South-East Asia Region accounts for more than 174,000 maternal and 1.3 million neonatal deaths every year, which is approximately a third of the global burden. The region also accounts for one million stillbirths and 3.1 million deaths of children under five years of age annually. Thus, the South East Asia region faces a great challenge in reducing maternal, newborn and child mortality as targeted in the Millennium Development Goals 4 and $5 .^{9}$

In developing countries, high risk pregnancy should be managed at peripheral centres with proper facilities, antenatal visits and timely referral service ${ }^{10}$ Reducing the worldwide maternal mortality ratio by 75\% between 1990 and 2015 is the target of Millennium Development Goal $5 .{ }^{8}$ Improving maternal and newborn health is a concerned area of interest to the international health community, especially for the World Health Organization. Since the Millennium Declaration in 2000 and the establishment of the Millennium Development Goals, the focus on improving maternal and newborn health has intensified. ${ }^{11}$

Maternal mortality remains a major challenge to health system worldwide. Reliable information about the rates and trends in maternal mortality is essential for resource mobilization, planning and assessment of progress towards Millennium Development Goal 5 by reducing the maternal mortality ratio as target by $2015 .{ }^{12}$

Child health is the purview of paediatrics and it is concerned with the health of infants, children and adolescents, their growth and development, and their opportunity to achieve full potential as adults. ${ }^{13}$ Worldwide, 7.6 million under five years children die every year. Over two-thirds of these early child deaths are due to conditions that could be prevented or treated with access to simple, affordable interventions. Leading causes of death in under-five children are pneumonia, diarrhoea, malaria and health problems during the first month of life. Over one third of all child deaths are linked to malnutrition. Children in low-income countries are nearly 18 times more at risk to die before the age of five than children in high-income countries. ${ }^{14}$

The reduction of maternal and child deaths is a high priority for the international community, especially in view of the increased attention on the Millennium Development Goals 4 and $5 .{ }^{15}$ The South East Asia region accounts for almost one-third of global mortality in neonates and children under 5 years of age. Despite of wide disparities in socio-economic and health indicators, many countries in this region are unlikely to reach Millennium Development Goals 4 and $5 .^{1}$

\section{LITERATURE SEARCH METHODS}

The aim of this paper is to assess the maternal and child health status in different countries of South East Asia Region by reviewing the available literature. It focuses on related issues and challenges of maternal and child health. Literature published in Pub Med, Lancet, Medline, WHO and Google web pages from 2000 to 2012 were searched for this purpose. Referencing software EndNote was used to manage the references. 
The maternal and child health status can be assessed by using different variables such: total fertility rate, contraceptive prevalence, maternal mortality ratio, antenatal care coverage, births attended by skilled health personnel, availability of basic essential obstetric care and availability of comprehensive essential obstetric care, prevalence of low birth weight, perinatal mortality rate, neonatal mortality rate, infant mortality rate, under five mortality rate, prevalence of positive syphilis serology in pregnant women, prevalence of anaemia in women, percentage of obstetric and gynaecological admissions owing to abortion, reported prevalence of women with genital mutilation, prevalence of infertility in women, reported incidence of urethritis in men, prevalence of HIV infection in pregnant women, knowledge of HIV-related preventive practices and so on. ${ }^{2}$ In this paper,focuses was on some selected variables: maternal mortality ratio, births attended by skilled health personnel, contraceptive prevalence, adolescent fertility, antenatal care coverage, perinatal mortality rates, infant mortality rates and under five mortality rates of some particular countries of South East Asia: Bangladesh, India, Nepal, Sri-Lank and Thailand and Pakistan from East Mediterranean Region.

\section{MATERNAL AND CHILD HEALTH SITUATION OF REGION:}

The South East Asia Region alone accounts for approximately one-third of the global maternal and child deaths annually. Maternal health and neonatal health are interrelated. The persistent burden of maternal and neonatal health globally, and in the South East Asian Region in particular, has been a major challenge to the achievement of both MDGs 4 and 5 as high rates of neonatal deaths contribute to infant and under-5 mortality inhibiting progress towards the MDG 4 target of reducing child mortality by two-thirds between 1990 and 2015. ${ }^{16}$ Table- 1 shows progress and existing situation of maternal and child health in South East Asia Region.

\section{Maternal and Child Health Situation in Different Countries}

Bangladesh: This country has made commendable progress in achieving Millennium Development Goals 4 and 5 . Since 1990, there has been a remarkable reduction in maternal and child mortality, with an estimated $57 \%$ reduction in child mortality and $66 \%$ in maternal mortality. This review paper highlights that, whereas Bangladesh is on track for achieving MDG 4 and 5, progress in universal access to reproductive health is not yet at the required pace to achieve the targets set for 2015. In addition, Bangladesh needs to further augment activities to get better newborn health and promote skilled attendance at birth. ${ }^{18}$ In South East Asia, child and infant mortality has reduced considerably but the neonatal mortality rate is still high. Newborn care is immense importance for the proper development and healthy life of a baby. A study in Bangladesh revealed an urgent need to educate mothers, and train traditional birth attendants and health workers on clean delivery practices, early neonatal care and prevention of delivery complications. ${ }^{19}$

India: Although some progresses have been made, achievement of the Fifth Millennium Development Goal (75\% reduction in maternal mortality ratio from 1990 by 2015 ) target seems to be unattainable by $2015 .^{20}$ The countdown database to track the maternal and child survival rate, as set by the Millennium Development Goal, reported recently that India's progress is not satisfactory in reducing newborn and child deaths. ${ }^{21}$ The findings of the next research show that the utilization of maternal and child health care services among adolescent women is far from satisfactory level in India. A little over $10 \%$ of adolescent women utilized antenatal care, about $50 \%$ utilized safe delivery services and about $41 \%$ of the children of adolescent women received full immunization. ${ }^{22}$

Nepal: The maternal mortality rate looks set to drop to its target of 134 per 100, 000 live births by 2015 from 539

Table-1. Maternal Child Health Related Indicators among Regions ${ }^{17}$

\begin{tabular}{|c|c|c|c|c|c|c|}
\hline Indicators of Maternal and Child Health & Africa & America & Europe & $\begin{array}{l}\text { Eastern } \\
\text { Mediterranean }\end{array}$ & Western Pacific & $\begin{array}{l}\text { South-East } \\
\text { Asia }\end{array}$ \\
\hline Children Aged $<5$ years underweight (\%) & NA* & NA & NA & NA & NA & NA \\
\hline Under-Five Mortality Rate per thousand & 127 & 18 & 13 & 72 & 21 & 59 \\
\hline Measles Immunization Coverage (\%) & 69 & 93 & 94 & 82 & 93 & 76 \\
\hline MMR(per 100000 live births) & 620 & 66 & 21 & 320 & 51 & 240 \\
\hline Births Attended By Skilled Health Personnel (\%) & NA & NA & NA & NA & NA & NA \\
\hline Contraceptive Prevalence (\%) & 24.4 & 74.4 & 70.7 & 42.2 & 80.2 & 57.5 \\
\hline Adolescent Fertility per thousand & 117 & 63 & 24 & 41 & 11 & 54 \\
\hline Antenatal Care Coverage (\%): at least 1 visit & 74 & 95 & 97 & 68 & 91 & 76 \\
\hline Unmet Need for Family Planning (\%) & 24.4 & 8.9 & 9.7 & 20.3 & 3.7 & 12.7 \\
\hline
\end{tabular}

*NA- Not Available 
per 100,000 live births in 1991. Under 5 child mortality rate in Nepal is on track to achieve the target of 54 per 1000 live births by 2015 compared with 158 per 1000 live births in $1991 .{ }^{23}$ Similarly, next study addressed the correlates and consequences of antenatal care utilization in Nepal and it showed that maternal education, even at low levels, significantly increases the use of antenatal care; paternal education plays a more important role in the use of routine antenatal care. ${ }^{24}$ The details situation of Millennium Development Goals 4 and 5 are presented in following table. mortality rate is 50 per 1000 . The trend of maternal and neonatal mortality looks at slow progress even though numerous initiatives; it is uncertain whether country will achieve Millennium Development Goals 4 and 5 by 2015. ${ }^{31}$

Similarly, Pakistan is committed to achieving a reduction in infant mortality rate from 72 to $<55$ per 1000 live births, the newborn mortality rate from 55 to $<40$ per 1000 live births and the maternal mortality rate from 276 per 100,000 to 140 per 100,000 live births by 2015 . Maternal,

Table 2. Trends of Millennium Development Goals 4 and 5 in Nepal 1990 to 201123-30

\begin{tabular}{|c|c|c|c|c|c|c|}
\hline $\begin{array}{l}\text { Indicators of Millennium Development } \\
\text { Goals(MDGs) }\end{array}$ & $\begin{array}{l}\text { NFHS* } \\
1991\end{array}$ & $\begin{array}{l}\text { NFHS** } \\
1996\end{array}$ & NDHS 2001 & NDHS 2006 & $\begin{array}{l}\text { NDHS } \\
2011\end{array}$ & MDGs Target 2015 \\
\hline \multicolumn{7}{|l|}{ MDG -4 } \\
\hline Infant Mortality per thousand & 106 & 78.5 & 64 & 48 & 45 & 34 \\
\hline Under 5 Mortality per thousand & 158 & 118.3 & 91 & 61 & 54.5 & 54 \\
\hline \multicolumn{7}{|l|}{ MDG -5 } \\
\hline Antenatal Care Coverage at Least One \% & NA & NA & NA & 43.7 & 58.3 & NA \\
\hline $\begin{array}{l}\text { Delivery Conducted by Skill Birth } \\
\text { Attendants \% }\end{array}$ & 7 & 9 & 11 & 10 & 36 & 60 \\
\hline Institutional Delivery \% & NA & NA & NA & 17.7 & 35.3 & NA \\
\hline $\begin{array}{l}\text { Maternal Mortality Ratio (MMR) per } 100 \\
\text { thousands live births }\end{array}$ & 830 & 539 & 415 & 181 & 229 & 134 \\
\hline Teenage Pregnancy per thousand & NA & NA & 84 & 106.3 & 81 & NA \\
\hline Contraceptive Prevalence Rate \% & 24 & 28.8 & 39.3 & 48 & 47.7 & 67 \\
\hline
\end{tabular}

* Nepal Family Health Survey, ** Nepal Demographic and Health Survey

Pakistan: The maternal mortality ratio remains high at between 350 and 500 per 100,000 live births and neonatal newborn and child health care plays a key role in reducing poverty and promoting social and economic development. Improvement in maternal and child health is a priority

Table-3. Maternal Child Health Related Indicators among Countries ${ }^{17}$

\begin{tabular}{|c|c|c|c|c|c|c|c|c|c|c|c|c|c|}
\hline $\begin{array}{l}\text { Indicators of } \\
\text { Maternal and Child } \\
\text { Health }\end{array}$ & 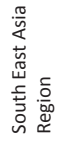 & 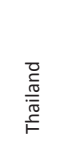 & $\begin{array}{l}\frac{c}{0} \\
\stackrel{\mathbb{N}}{J} \\
\frac{E}{\infty}\end{array}$ & $\begin{array}{l}\frac{\pi}{0} \\
\mathbb{0} \\
\stackrel{0}{0} \\
\stackrel{0}{\Xi}\end{array}$ & 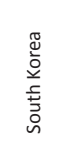 & 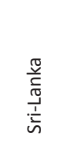 & $\frac{\stackrel{y}{ \pm}}{\frac{0}{0}}$ & 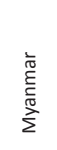 & $\begin{array}{l}\overline{0} \\
\frac{0}{2} \\
2\end{array}$ & $\begin{array}{l}\frac{c}{\tilde{y}} \\
\frac{0}{0} \\
\frac{\pi}{00} \\
\frac{\tilde{D}}{0} \\
\infty\end{array}$ & 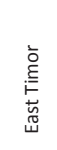 & $\stackrel{\frac{\pi}{\pi}}{\underline{\frac{\pi}{5}}}$ & 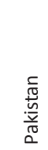 \\
\hline $\begin{array}{l}\text { Children Aged }<5 \\
\text { years underweight } \\
(\%)\end{array}$ & NA & 7.0 & 12.0 & 19.6 & 20.6 & 21.6 & 25.7 & 29.6 & 38.8 & 41.3 & 41.5 & 43.5 & 31.3 \\
\hline $\begin{array}{l}\text { Under-Five Mortality } \\
\text { Rate }\end{array}$ & 59 & 13 & 79 & 39 & 33 & 16 & 13 & 71 & 48 & 52 & 56 & 66 & 87 \\
\hline $\begin{array}{l}\text { Measles } \\
\text { Immunization } \\
\text { Coverage (\%) }\end{array}$ & 76 & 98 & 98 & 82 & 98 & 96 & 98 & 87 & 79 & 89 & 70 & 71 & 80 \\
\hline $\begin{array}{l}\text { MMR(per } 100 \\
\text { thousands live } \\
\text { births) }\end{array}$ & 240 & 48 & 200 & 240 & 250 & 39 & 37 & 240 & 380 & 340 & 370 & 230 & 260 \\
\hline $\begin{array}{l}\text { Births Attended } \\
\text { by Skilled Health } \\
\text { Personnel (\%) }\end{array}$ & NA & $\geq 99$ & 72 & 73 & 97 & $\geq 99$ & 95 & 37 & 19 & 18 & 30 & 47 & 39 \\
\hline $\begin{array}{l}\text { Contraceptive } \\
\text { Prevalence (\%) }\end{array}$ & 57.5 & 81.1 & NA & 61.4 & 68.6 & 68.0 & 34.7 & 41.0 & 48.0 & 55.8 & 22.3 & 56.3 & 27 \\
\hline $\begin{array}{l}\text { Adolescent Fertility } \\
\text { Rate per thousands }\end{array}$ & 54 & 43 & 46 & 52 & 1 & 28 & 14 & 17 & 106 & 133 & 59 & 45 & 20 \\
\hline $\begin{array}{l}\text { Antenatal Care } \\
\text { Coverage (\%): at } \\
\text { least } 1 \text { visit }\end{array}$ & 76 & 99 & 88 & 93 & 97 & 99 & 99 & 80 & 44 & 52 & 84 & 75 & 61 \\
\hline $\begin{array}{l}\text { Unmet Need for } \\
\text { Family Planning (\%) }\end{array}$ & 12.7 & 3.1 & NA & 9.1 & NA & 7.3 & NA & 19.1 & 24.6 & 16.8 & 3.8 & 12.8 & 24.9 \\
\hline
\end{tabular}


agenda of the Government of Pakistan.Tough, Pakistan seems unlikely to achieve MDGs 4 and 5 by $2015 .{ }^{32}$

Sri Lanka: This country has exemplary records in maternal and child health care in South East Asia. The maternal mortality ratio and the other indices of maternal and child health have shown uninterrupted step up since 1930. Public health midwives provide care at the doorstep and $99 \%$ deliveries occur in hospitals. Although on the target of the Millennium Development Goals 4 and 5, still remain some challenges on maternal and child health such as postpartum haemorrhage and unsafe abortion, and perinatal deaths due to congenital abnormalities and prematurity. ${ }^{33}$

Thailand: There is high equity of coverage in key maternal child health services throughout the country. Inequitable health outcomes are largely due to socioeconomic factors, especially differences in the educational level of mothers or caregivers, whereas mothers or caregivers had no formal education, all outcome indicators were worse than in the group with the highest level of education. ${ }^{34}$ Regarding the equity of access to reproductive health services, there were very high coverage of family planning (79.6\%), universal antenatal care $(98.9 \%)$ and skilled birth attendance (99.7\%), with very small socioeconomic and geographic disparities. But, the public sector played a dominant role in maternity care: $90.9 \%$ of all deliveries in 2009. ${ }^{35}$ Table 2 shows the brief scenario of maternal child health in different South East Asian countries.

Worldwide, child mortality is declining continuously. The total number of deaths of children under 5 is dropped from 12.4 million in 1990 to 8.1 million in 2009 . The mortality rate in children under 5 years has fallen correspondingly from 89 per 1000 live births in 1990 to 60 per 1000 live births in 2009, representing a reduction of about one third. At the same time, the average annual rate of decline has gone faster over the period 2000-2009 compared with the 1990s. ${ }^{14}$ The level of mortality, however, remains alarmingly high in certain regions of the world. The coverage of key child health interventions against often fatal diseases remains inadequate such as oral rehydration therapy and zinc for diarrhoea, and case management with antibiotics for pneumonia.

Table 4: Average Annual Rate of Decline (\%) in Children Under 5 Year Mortality ${ }^{14}$ (1990-1999 and 2000-2009)

\begin{tabular}{lcc}
\hline Regions of WHO & 1990-1999 & 2000-2009 \\
\hline Africa & 1.0 & 2.5 \\
Americas & 4.2 & 4.3 \\
South-East Asia & 2.7 & 4.0 \\
Europe & 3.7 & 5.6 \\
Eastern Mediterranean & 1.8 & 2.1 \\
Western Pacific & 2.4 & 5.4 \\
Global & 2.3 & 2.7 \\
\hline
\end{tabular}

Regional estimates of under five mortality rate in 2003 was vary from a low of nine per 1000 live births for developed countries to a high of 172 per 1000 live births in subSaharan Africa. In relation to the Millennium Development Goal 4, the difference between regions in the reduction of under five mortality rate over the period 1990-2003 was remarkable. Northern Africa, Latin America, Caribbean and South-Eastern Asia have made rapid progress, but other regions are clearly not in track. ${ }^{36}$

The countries in South East Asia have wide disparities in socio-economic and health indicators. This region accounts for almost one-third of global mortality in neonates and children under 5 years of age, and many countries in this region are unlikely to attain Millennium Development Goal 4. Although maternal and child mortality are on the decline in South East Asia, there are still major disparities, and greater equity is key to achieve the Millennium Development Goals. ${ }^{8}$

\section{CONCLUSION}

In the South East Asia, there are wide discrimination, inequality and disparity in socio-economic and health status among the countries. More than one-third of maternal and child deaths of global mortality occur in this region. Many countries in this region are unlikely to attain Millennium Development Goals 4 and 5, even though maternal child health is the priority agenda of all the countries of this region.

\section{ACKNOWLEDGEMENT}

I wish to acknowledge to all writers, editors and publishers of the reviewed literatures. I would like to express my gratitude to Prof. V. Raman Kutty for his guidance and editing of this manuscript. Similarly, I extend my sincere gratitude to the Doctorial Advisory Committee (DAC) members for their consistent intellectual support for creation of this article.

\section{REFERENCES}

1. Nair H, Arya G, Vidnapathirana J, Tripathi S, Talukder SH, Srivastava V. Improving Neonatal Health in South-East Asia. Public Health. 2012;126(3):223-6

2. World Health Organization. Reproductive Health Indicators: Guidelines for Their Generation and Analysis for Global Monitoring. World Health Organization: WHO Press, 20 Avenue Appia, 2011, Geneva 27, Switzerland, 2006

3. UNFPA - Master Plans for Development [Internet]. [Cited $2012 \mathrm{Apr}$ 29]; Available from: http://www.unfpa.org/public/home/sitemap/ icpd/International-Conference-on-Population-and-Development.

4. Kushwaha AS. Family Health: Maternal Health. In: R.Bhalwar, R. Vaidya, R.Tilak, R.Gupta, R.Kutne. Text Book of Public Health and Community Medicine, 1st edn. India: Department of Community Medicine, Armed Forces Medical College, Pune, in collaboration with WHO, India Office, New Delhi. 2009;809-95. 
5. World Health Organization. Maternal Mortality. Media Centre. 2012.[Cited 2012 Fem 28];Available from:http://www.who.int/ mediacentre/factsheets/fs348/en/index.html

6. Souza JP, Gulmezoglu AM, Carroli G, Lumbiganon P, Qureshi Z. The World Health Organization Multi-Country Survey on Maternal and Newborn Health: Study Protocol. BMC Health Serv Res. 2011;11:286.

7. Nwaru BI, Klemetti R, Kun H, Hong W, Yuan S, Wu Z, Hemminki E. Maternal Socio-Economic Indices for Prenatal Care Research in Rural China. Eur J Public Health. 2011; doi: 10.1093/eurpub/ckr182.

8. Ross L, Simkhada P, Smith WC. Evaluating Effectiveness of Complex Interventions Aimed at Reducing Maternal Mortality in Developing Countries. J Public Health (Oxf). 2005;27(4):331-7.

9. Elizabeth Lule, Ramana GNV, Nandini Ooman, Joanne Epp Dale Huntington, James E, Rosen. Achieving the Millennium Development Goal of Improving Maternal Health: Determinants, Interventions and Challenges. HNP Discussion Paper, Health Nutrition and Population, World Bank, 2008.

10. Bajwa SK, Bajwa SJ, Kaur J, Singh K, Kaur J. Is Intensive Care the Only Answer for High Risk Pregnancies in Developing Nations? J Emerg Trauma Shock. 2010;3(4):33 -6.

11. Coltart CE, Souza JP, Gulmezoglu AM. Prioritizing WHO Normative Work on Maternal and Perinatal Health: a Multi-Country Survey. Reprod Health. 2011;8:p.30.

12. Hogan MC, Foreman KJ, Naghavi M, et al. Maternal Mortality for 181 Countries, 1980-2008: a Systematic Analysis of Progress towards Millennium Development Goal 5. Lancet. 2010;375(9726): 1609-23.

13. Webster. Webster's New World TM, Medical Dictionary, 3rd Edn 2008. [Cited 2012 March 1];Available from: http://www.medterms. com/script/main/art.asp

14. World Health Organization. Children: Reducing Mortality. Media Centre, 2012.[Cited 2012 Feb 29];Available from: http://www.who. int/mediacentre/factsheets

15. Acuin CS, Khor GL, Liabsuetrakul T et al. Maternal, Neonatal, and Child Health in South-East Asia: Towards Greater Regional Collaboration. Lancet. 2011;377(9764):516-25.

16. Islam M. Progress towards Achieving Millennium Development Goal 5 in South-East Asia. Brit J Obstet Gynecol. 2011;118(Suppl 2): 6-11.

17. WHO World Health Statistics 2011 [Internet]. WHO [cited 2012 Ap 5];Availablefrom:http://www.who.int/gho/publications/world_ health_statistics/2011

18. Chowdhury S, Banu LA, Chowdhury TA, Rubayet S, Khatoon S Achieving Millennium Development Goals 4 and 5 in Bangladesh. 2011;118(Suppl 2):36-46.

19. Shahjahan M, Ahmed MR, Rahman MM, Afroz A. Factors Affecting Newborn Care Practices in Bangladesh. Paediatr Perinat Epidemiol. 2012;26(1):13-8
20. Rai RK, Tulchinsky TH. Addressing the Sluggish Progress in Reducing Maternal Mortality in India. Asia Pac J Public Health. 2012.

21. Ghosh R. Child Mortality in India: A Complex Situation. World J Pediatr. 2012;8(1):p.11-8.

22. Singh L, Rai RK, Singh PK. Assessing the Utilization Of Maternal and Child Health Care among Married Adolescent Women: Evidence from India. J Biosoc Sci. 2012;44(1):p.1-26.

23. Malla DS, Giri K, Karki C, Chaudhary P. Achieving Millennium Development Goals 4 and 5 in Nepal. 2011;118(Suppl 2): p.60-8.

24. Halim N, Bohara AK, Ruan X. Healthy Mothers and Healthy Children: Does Maternal Demand for Antenatal Care Matter for Child Health in Nepal? Health Policy Plan. 2010;26(3):p.242-56.

25. Nepal Family Health Survey 1991 - Google Search [Internet]. [cited 2012 Apr 5];Available from: http://www.google.co.in

26. Nepal Family Health Survey 1996 - Google Search [Internet]. [cited 2012 Apr 5];Available from: http://www.google.co.in

27. Nepal demographic and health survey: key findings, 2001- Google Search [Internet]. [cited 2012 Apr 5];Available from: http://www. google.co.in

28. Nepal demographic and health survey 2006- Google Search [Internet]. [cited 2012 Apr 5]; Available from: http://www.google. co.in

29. Annual Report - DOHS, Ministry of Health and Population, Nepal 2009/2010. [Internet]. [cited 2012 Apr 8];Available from: http:// www.xenomed.com/community

30. Preliminary Results of DHS 2011 Nepal. Google Search [Internet] [cited 2012 Apr 6];Available from: http://www.google.co.in

32. Jafarey S, Kamal I, Qureshi AF, Fikree F. Safe Motherhood in Pakistan. Int J Gynaecol Obstet. 2008;02(2):179-85.

32. Mahmud G, Zaman F, Jafarey S, Khan RL, Sohail R, Fatima S. Achieving Millennium Development Goals 4 and 5 in Pakistan. Brit J Obstet Gynecol. 2011;118(2):69-77.

33. Senanayake $H$, Goonewardene $M$, Ranatunga A, Hattotuwa $\mathrm{R}$, Amarasekera $\mathrm{S}$, Amarasinghe I. Achieving Millennium Development Goals 4 and 5 in Sri Lanka. Brit J Obstet Gynecol. 2011;118(2):78-87.

34. Limwattananon S, Tangcharoensathien V, Prakongsai P. Equity in Maternal and Child Health in Thailand. Bull World Health Organ. 2010,88(6):420-7.

35. Kongsri, S., et al., Equity of access to and utilization of reproductive health services in Thailand: national Reproductive Health Survey data, 2006 and 2009. Reprod Health Matters, 2011;19(37):86-97.

36. World Health Organization. Health and the Millennium Development Goals. World Health Organization: WHO Press, 20 Avenue Appia, 2011, Geneva 27, Switzerland, 2005. 